"This is the peer reviewed version of the following article: [ A Systematic Study of Metal Triflates in Catalytic Transformations of Glucose in Water and Methanol: Identifying the Interplay of Brønsted and Lewis Acidity.. I

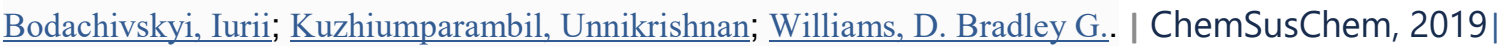
which has been published in final form at

[https://onlinelibrary.wiley.com/doi/abs/10.1002/cssc.201900292]This article may be used for non-commercial purposes in accordance with Wiley Terms and Conditions for Self-Archiving 


\title{
A systematic study of metal triflates in catalytic transformations of glucose in water and methanol: identifying the interplay of Brønsted and Lewis acidity
}

\author{
Iurii Bodachivskyi, ${ }^{[a]}$ Unnikrishnan Kuzhiumparambil[ ${ }^{[b]}$ and D. Bradley G. Williams ${ }^{\star[a]}$
}

\begin{abstract}
The specific type of acidity associated with given metal trifloromethanesulfonates (Brønsted- or Lewis acidity) dramatically influences the course of reactions and it is possible to select for disaccharides, fructose, methyl glucosides, or methyl levulinate. Glucose is transformed into a range of value added molecules in water and methanol under the action of acidic metal triflates as catalysts, including their analogous Brønsted acid-assisted, or Brønsted base-modified systems. We present a systematic study of a range of metal triflates in methanol and water, pinning down the preferred conditions to select for each product.
\end{abstract}

\section{Introduction}

The production of bulk chemicals from naturally derived materials is a foundation of sustainable chemical industrial development. Among the various resources that are available, cellulose-derived glucose in principle possesses the scale of manufacture and overall availability to sustain a large chemical industry. ${ }^{[1]}$ In the presence of an acid catalyst, glucose may be converted into a large portfolio of valuable organic building block chemicals (platform molecules), all of which are realistic contenders to substitute petrochemical products. ${ }^{[1-3]}$ Despite this promise, the acid-catalyzed valorization of glucose is challenging: complexities arise because of the low selectivity of processes that are typically performed in water and which require both Lewis and Brønsted acid catalysts, as pictorially presented in Scheme S1 (Supporting information). ${ }^{[1]}$ It is considered that Lewis acids promote the isomerization of glucose into fructose at moderate temperatures, ${ }^{[3,4]}$ and at elevated temperatures facilitate retroaldol reactions into low-molecular-weight sugars from which $\alpha$ hydroxy acids are produced. ${ }^{[5]}$ In turn, Brønsted acids usually catalyze dehydration of fructose into 5-(hydroxymethyl)furfural (HMF) and rehydration thereof into levulinic acid under more

[a] I. Bodachivskyi, Prof. Dr. D.B.G. Williams

University of Technology Sydney

School of Mathematical and Physical Sciences

Broadway NSW 2007, PO Box 123 Broadway NSW 2007 (Australia)

E-mail: Bradley.Williams@uts.edu.au

[b] Dr. U. Kuzhiumparambil

University of Technology Sydney

Climate Change Cluster (C3)

Broadway NSW 2007, PO Box 123 Broadway NSW 2007 (Australia)

Supporting information for this article is given via a link at the end of the document. forcing reaction conditions. ${ }^{[6]}$ While Brønsted acidity is achievable by the addition of protic acids to the media, it is more difficult to ensure Lewis acidity, due to deactivation of many Lewis acids in aqueous solvents. ${ }^{[7]}$ The differing role of the acid catalysts at each stage of the conversion of glucose, along with difficulties to sustain Lewis acidity in water, requires the judicious selection of robust catalysts that are capable of providing the requisite activity to enable the substrate to be transformed into the desired product in high yield and selectivity.

The general understanding of the role of solid acid catalysts in these processes has improved over the past few years, owing to several elegant studies. ${ }^{[8-10]}$ On the other hand, metal triflates are water-tolerant homogeneous Lewis acid catalysts, which has fostered their use in a number of chemical processes in aqueous and protic media, including the synthesis of platform molecules. ${ }^{[7,11-14]}$ Replacing the aqueous solvent with alcohols permits the conversion of carbohydrates into desirable platform molecules in enhanced yields and sometimes under milder reaction conditions. ${ }^{[6,15-17]}$ In the present work, we detail a systematic study of a range of metal triflates and the responses of the reactions in question to the prevailing conditions. In particular, we probe the type of acidity (Brønsted or Lewis) associated with metal triflates and their performance in transformations of glucose into defined valuable molecules, in aqueous media and methanol. This helps to build an improved and more unified view of how to structure chemical processing of glucose into platform chemicals. In particular, we probe the conversion of glucose into disaccharides, into fructose and methyl glucosides (MG), and into methyl levulinate (MLev). Along the way, we consider HMF and 5-(methoxymethyl)furfural (MMF), which are intermediates towards MLev.

\section{Results and Discussion}

Metal triflates are efficient in the synthesis of some platform molecules in both aqueous and alcohol media at elevated temperatures $\left(180-240^{\circ} \mathrm{C}\right) .{ }^{[14-16]}$ Highly selective transformations at lower temperatures are desirable and was an object of the present study. To achieve this, the activity of a number of metal triflates $\left(\mathrm{Hf}(\mathrm{OTf})_{4}, \mathrm{Sn}(\mathrm{OTf})_{2}, \ln (\mathrm{OTf})_{3}, \mathrm{Al}(\mathrm{OTf})_{3}, \mathrm{AgOTf}, \mathrm{LiOTf}\right.$ $\mathrm{La}(\mathrm{OTf})_{3}$, or $\left.\mathrm{Y}(\mathrm{OTf})_{3}\right)$, Brønsted acids $\left(\mathrm{TsOH}\right.$ and $\left.\mathrm{H}_{3} \mathrm{PO}_{4}\right)$ and Lewis acid-assisted Brønsted acids ( $\mathrm{La}(\mathrm{OTf})_{3} / \mathrm{H}_{3} \mathrm{PO}_{4}$ $\mathrm{La}(\mathrm{OTf})_{3} / \mathrm{TsOH}$ ) was explored for the conversion of glucose at lower temperatures, and in water or methanol under reflux at atmosphere pressure. In water, fructose, an isomerization product of glucose, is the desired and expected major product,,$^{[3,4]}$ but the 
maximum yield of fructose was only $9 \mathrm{~mol} \%$ (based on glucose, Table S1). Metal triflates such as $\mathrm{Sn}(\mathrm{OTf})_{2}$ and $\mathrm{Hf}(\mathrm{OTf})_{4}$ promoted the formation of dark-brown high molecular weight by-product humins (insoluble condensation products of HMF with saccharides $^{[18]}$ - HMF is a dehydration product of fructose), accounting for the substantial mass losses noted. In contrast, AgOTf, or LiOTf showed no catalyst activity, potentially due to weak complexation with the substrate. Interestingly, the dominant reaction noted with Brønsted acids or Lewis acid-assisted Brønsted acids was the catalyzed condensation of glucose into isomaltose and oligosaccharides, as pictorially represented in Scheme 1. While this condensation process has been known since Emil Fischer's day, most current research shows a distinct focus on enzymatic methods, with little information relating to the targeted chemical synthesis of disaccharides. ${ }^{[19-22]}$ A selective chemical method would therefore provide an exciting alternative to enzymatic methods. As expected, the self-condensation of glucose was more efficient in concentrated aqueous solutions (30 wt $\%$ glucose in water) and extended reaction times (12 h). The highest conversion of glucose (43 wt\%, of which $42 \mathrm{wt} \%$ is accounted for immediately below, implying $98 \%$ selectivity to the named products) into saccharide condensation products was achieved by employing a combination of $\mathrm{La}(\mathrm{OTf})_{3} / \mathrm{H}_{3} \mathrm{PO}_{4}$, and isomaltose was isolated as a main product (yield $17 \mathrm{wt} \%$ based on glucose, Table S1) together with other water-soluble di-, triand oligosaccharides (yield 5, 6 and 14wt\%, respectively, Table S2). For comparison, analogous enzymatic processes provide isomaltose in $14 \mathrm{wt} \%$ and oligosaccharides in $4 \mathrm{wt} \%$ yield. ${ }^{[19]}$ In our hands, if water was allowed to distill slowly from the reaction mixture to promote condensation reactions, trisaccharides and oligomeric products predominated, along with water-insoluble material the color of caramel. In this reaction, it is the Brønsted acidity associated with the catalysts, including the metal triflates, ${ }^{[12,13,23,24]}$ that leads to the self-condensation of glucose.

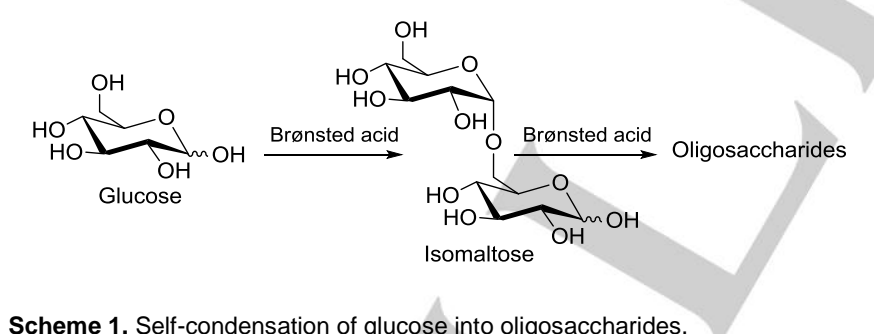

A density-functional study at B3LYP/ $6-31+g(d)$ level of theory considering the experimental reaction parameters (temperature, pressure, solvation) found the transition state towards isomaltose to be substantially more stable than those towards other disaccharides (Scheme S2 shows the series of glucose dimers considered; Scheme S3 shows a reaction mechanism with intermediates). The finding implies a kinetic preference for isomaltose (Figure S1). This observation, coupled with a stable product (thermodynamically the second most favored product of the entire series, Table S3), would account for the predominance of isomaltose over other glucose disaccharides under Brønsted acid-catalyzed conditions, as observed experimentally.

Aldose-ketose isomerization, required for the glucose-fructose conversion, is more efficient in alcohols than water, affording alkyl glycosides (glucoside (non-isomerization product) and fructoside (isomerization product)) as major products. ${ }^{[3,8,17]}$ Because the yields of fructose were low in our first set of reactions, consistent with dominant Brønsted acid activity, and to improve the outcome towards fructose, we adopted a two-step one-pot process conducting the isomerization in methanol (under reflux at atmospheric pressure, $1 \mathrm{~h}$ ), and then the hydrolysis of methyl glycosides into fructose and glucose in water (under reflux at atmospheric pressure, $1 \mathrm{~h}$; Table 1 gives results after the second step).

Table 1. Acid-catalyzed transformation of glucose in methanol and water ${ }^{[a]}$

\begin{tabular}{|c|c|c|c|c|c|}
\hline Acid catalyst & $\begin{array}{l}\text { Conv } \\
{[\%]}\end{array}$ & $\begin{array}{l}\text { Fructose } \\
\text { yield [\%] }\end{array}$ & $\begin{array}{l}\text { MG } \\
\text { yield [\%] }\end{array}$ & $\begin{array}{l}\mathrm{pH} \\
0.01 \mathrm{M}, \\
\mathrm{H}_{2} \mathrm{O}^{[\mathrm{b}]}\end{array}$ & $\begin{array}{l}\mathrm{pH} \\
0.01 \mathrm{M}, \\
\mathrm{MeOH}^{[\mathrm{b}}\end{array}$ \\
\hline $\mathrm{La}(\mathrm{OTf})_{3} / \mathrm{H}_{3} \mathrm{PO}_{4}$ & 12 & 0 & 9 & 2.04 & 0.72 \\
\hline $\mathrm{Hf}(\mathrm{OTf})_{4}$ & 41 & 3 & 9 & 2.05 & 0.50 \\
\hline $\mathrm{TsOH}$ & 8 & 0 & 7 & 2.08 & 0.59 \\
\hline $\mathrm{H}_{3} \mathrm{PO}_{4}$ & 0 & 0 & 0 & 2.21 & 2.74 \\
\hline $\mathrm{La}(\mathrm{OTf})_{3} / \mathrm{TsOH}$ & 7 & 0 & 5 & 2.39 & 1.07 \\
\hline $\mathrm{Sn}(\mathrm{OTf})_{2}$ & 29 & 4 & 9 & 2.61 & 0.53 \\
\hline $\ln (\mathrm{OTf})_{3}$ & 29 & 15 & 9 & 3.12 & 1.09 \\
\hline $\mathrm{Al}(\mathrm{OTf})_{3}$ & 42 & 24 & 5 & 3.60 & 1.75 \\
\hline $\mathrm{Al}(\mathrm{OTf})_{3} / \mathrm{TBP}^{[\mathrm{c}]}$ & 64 & 47 & 1 & 3.66 & 2.66 \\
\hline AgOTf & 0 & 0 & 0 & $\begin{array}{l}5.16 \\
4.85^{[d]}\end{array}$ & $\begin{array}{l}6.10 \\
4.04^{[d]}\end{array}$ \\
\hline LiOTf & 4 & 3 & 0 & 5.33 & 6.90 \\
\hline $\mathrm{La}(\mathrm{OTf})_{3}$ & 12 & 5 & 0 & $\begin{array}{l}6.31 \\
6.05^{[\mathrm{d}]}\end{array}$ & $\begin{array}{l}4.63 \\
3.77^{[d]}\end{array}$ \\
\hline$Y(O T f)_{3}$ & 6 & 2 & 2 & $\begin{array}{l}6.64 \\
6.02^{[\mathrm{d}]}\end{array}$ & $\begin{array}{l}3.98 \\
3.20^{[d]}\end{array}$ \\
\hline H-USY[e,17] & 72 & 55 & - & - & - \\
\hline
\end{tabular}

[a] Yields are specified in mol\% based on glucose; '0' or '99' for the product were identified on the basis of trace analysis by HPLC. OTf = trifluoromethanesulfonate; $\mathrm{TsOH}=p$-toluenesulfonic acid; TBP $=2,6$-ditert-butyl-4-methylpyridine. Reaction conditions: glucose $(50 \mathrm{mg})$, methanol (2 $\mathrm{mL})$, catalyst (20 mol\% based on glucose), reflux at atmosphere pressure, $1 \mathrm{~h}$, then solvent exchange with water $(2 \mathrm{~mL})$, reflux at atmosphere pressure, $1 \mathrm{~h}$. [b] pH readings were performed in triplicate in water or aqueous methanol $(98 \%$ alcohol $)$ at $20^{\circ} \mathrm{C}$. [c] Reaction conditions: glucose $(50 \mathrm{mg})$, methanol $(2 \mathrm{~mL}), \mathrm{Al}(\mathrm{OTf})_{3}(20 \mathrm{~mol} \%$ based on glucose), TBP (60 mol\% based on glucose), reflux at atmosphere pressure, $36 \mathrm{~h}$, then solvent exchange with water $(2 \mathrm{~mL})$, reflux at atmosphere pressure, 1 h. [d] pH values measured at $40^{\circ} \mathrm{C}$. [e] Reaction conditions: ${ }^{[17]}$ glucose $(125$ $\mathrm{mg})$, methanol $(4 \mathrm{~g}), \mathrm{H}$-USY zeolite $(75 \mathrm{mg}), 120^{\circ} \mathrm{C}, 2 \mathrm{~h}$, then addition of water $(2 \mathrm{~g}), 120^{\circ} \mathrm{C}, 1 \mathrm{~h}$. 
This approach has been employed favorably in the presence of zeolites. ${ }^{[8,17,25,26]}$ Glucose, fructose and MG (as a 1:1 mixture of $\alpha$ and $\beta$-anomers of methyl glucopyranoside, as established by quantitative NMR analysis of the product mixture after Step 2, Figure S2) were obtained after two-step processing in methanol and water; $\mathrm{Al}(\mathrm{OTf})_{3}$ was found to possess optimal Lewis acidity to drive the isomerization reaction ( $24 \mathrm{~mol} \%$ yield of fructose). Given that a) conversion of glucose into fructose is favored by Lewis acids and b) conversion of glucose or fructose into methyl glycosides is favored by Brønsted acidity (similar to the selfcondensation of glucose, mentioned above), then it might be possible to improve selectivity to fructose by minimizing the Brønsted acid activity associated with the metal triflate catalysts. 2,6-Di-tert-butyl-4-methylpyridine (TBP) is known to discriminate between Brønsted and Lewis acidity because it interacts exclusively with hydrogen cations due to the extreme steric hindrance exerted by the tert-butyl-groups, which prevents interactions at the $\mathrm{N}$ atom with any larger cations, ${ }^{[27]}$ including Al. ${ }^{[24]}$ Pleasingly, the addition of TBP as Brønsted base (3:1 based


production of $M G$ and simultaneously improved the selectivity to and yield of fructose, albeit that the process required longer reaction times (Table 1, Table S4). This outcome demonstrates that catalyst systems which display both Lewis and Brønsted acidity can be modulated towards Lewis acidity to develop improved chemical selectivity (see below and Table 1 for a discussion on the acidity of the metal triflates). It is worth noting that the yield of the isomerization product fructose $(47 \%)$, produced under mild processing conditions, compares very favorably with the industrially applied enzymatic method (42\%). ${ }^{[1]}$ In rare instances, higher yields of fructose are achievable under more forcing reaction conditions (Table 1). ${ }^{[17]}$

Interrogation of the product after step 1, by NMR spectroscopy, led to important observations. In particular, the first step delivers high yields of a combination of methyl fructosides and methyl glucofuranosides during the conversion in methanol, when the Lewis acid $\mathrm{Al}(\mathrm{OTf})_{3}$ is present, and only small amounts of glucopyranosides (Figure 1). This is entirely consistent with recent work with zeolite catalysts, in which methyl furanosides were also identified as kinetic products. ${ }^{[8]}$ In our work, in all instances, diagnostic signals map perfectly onto those previously determined for similar mixtures. ${ }^{[8]}$ As anticipated, the addition of TBP to $\mathrm{Al}(\mathrm{OTf})_{3}$ suppresses the Brønsted acidity associated with Lewis acid catalyst and favors the formation of methyl fructosides in preference to methyl glucosides (Figure 2). When only a Brønsted acid is present (TsOH), or Lewis acid-assisted Brønsted acid $\left(\mathrm{La}(\mathrm{OTf})_{3} / \mathrm{H}_{3} \mathrm{PO}_{4}\right)$, or hard Lewis acid $\left(\mathrm{Hf}(\mathrm{OTf})_{4}\right)$, very high yields of methyl glucosides are obtained (up to $94 \%$ as a mixture of glucopyranosides and glucofuranosides, Figures 3, S3 and S4) with no evidence for the formation of fructosides. The softer Lewis acid $\left(\mathrm{La}(\mathrm{OTf})_{3}\right)$ provides only little conversion into methyl glucofuranosides under the applied conditions (Figure S5). These observations also provide evidence that hard and soft Lewis acids $\left(\mathrm{Hf}(\mathrm{OTf})_{4}\right.$ and $\mathrm{La}(\mathrm{OTf})_{3}$, respectively) mostly catalyze the isomerization of glucose into fructose in water during the second step; with these acids, the gains of fructose after the two-step conversion in methanol and water are similar to those obtained after the one-step transformation in water (Table 1 and S1). Methyl glucofuranosides and fructosides are readily converted into glucose and fructose during the processing in water (i.e. the second step, Figure S2). In turn, glucopyranosides were somewhat stable to hydrolysis under the conditions we employed: in all cases where Lewis acids were present, the amount of MG after step 2 was identical to the amount of MG found after step 1 (formed in a 1:1 ratio, as determined by quantitative NMR spectroscopy after each step).

$\mathrm{pH}$ determinations of solutions of various metal triflates in water and methanol, respectively, revealed the strength of the Brønsted acids formed in solution (Table 1). Metal triflates are typically considered to be Lewis acids, but clearly possess Brønsted acidity, sometimes comparable to strong protic Brønsted acids ( $\mathrm{TsOH}$ and $\mathrm{H}_{3} \mathrm{PO}_{4}$ ). This phenomenon is caused by Lewis acidassisted Brønsted acidity through complexation of the metal center with the protic solvent and release of hydrogen cation (typically present as $\mathrm{H}_{13} \mathrm{O}_{6}{ }^{+}$in dilute aqueous solutions) ${ }^{[28]}$ as was disclosed earlier for $\mathrm{Al}(\mathrm{OTf})_{3}{ }^{[23,24]}$ This effect is observed in both media (water and methanol) and is prominent for $\mathrm{Hf}(\mathrm{OTf})_{4}$ and $\mathrm{Sn}(\mathrm{OTf})_{2}$. Certain mixed acids (Lewis + Brønsted), specifically the $\mathrm{La}(\mathrm{OTf})_{3} / \mathrm{H}_{3} \mathrm{PO}_{4}$ pair, deliver the highest Brønsted acidity (Table 1), consistent with our previous studies. ${ }^{[13]}$ TBP reduces the Brønsted acidity of metal triflates but this effect was noted in methanol only and rather little in the water, most likely due to the poor solubility of TBP in water.

When considering the combined experimental data, the following emerges:

a) the strongest Brønsted acids (where the acidity is due to a protic acid or an assisted Brønsted acid), as determined by $\mathrm{pH}$ measurements, provide the highest yields of disaccharides in aqueous media and of MG in methanol;

b) Lewis acids catalyze the isomerization of glucose into fructose, but those that induce the highest Brønsted acidity also promote the formation of methyl glucopyranosides and methyl glucofuranosides (in methanol) and humins;

c) TBP is capable of selectively neutralizing the Lewis acidassisted-Brønsted acidity while maintaining Lewis acidity in methanol and therefore improves the selectivity of the conversion of glucose into fructose.

With the view to converting glucose into other platform molecules, which requires elevated temperatures, we conducted the two-step processing in methanol for longer reaction times and at higher temperatures from $65^{\circ} \mathrm{C}$ to $120^{\circ} \mathrm{C}$ in the presence of $\mathrm{Al}(\mathrm{OTf})_{3}$ as catalyst (Figure 4), followed by hydrolysis in water. We used a sealed glass pressure-tube for temperatures above $65^{\circ} \mathrm{C}$. As is evident from Figure $4 a$, extended reaction times do not influence the yield of fructose (for solvent under reflux at ambient pressure) but do improve the conversion of glucose into MG, HMF, MMF, and MLev. Higher temperatures reduce the yield of fructose, due to its conversion into furaldehydes and their ultimate rehydration into MLev (Figures 4b-d). Arguably, methyl glucosides are also converted into MLev at elevated temperatures after hydrolysis into glucose. Furaldehydes appeared as their dimethyl acetals after the processing in methanol and these readily hydrolyzed into HMF and MMF after methanol-water solvent exchange (Figure S6). 


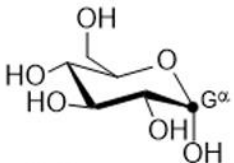

$\alpha$-D-Glucopyranose $3 \%$

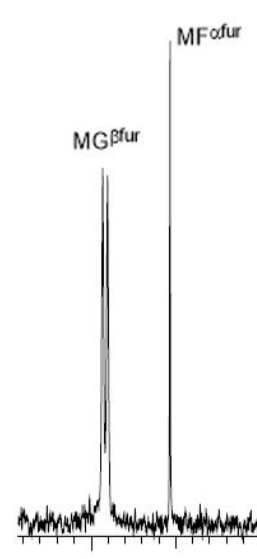

112<smiles>OC1CC(O)C(O)CC(O)O1</smiles>

$\beta-D-G l u c o p y r a n o s e$ $5 \%$



OMe

Methyl $\alpha$-D-Glucopyranoside $3 \%$<smiles>CO[C@H]1O[C@H](O)[C@@H](O)[C@H](O)[C@H](O)[C@H]1O</smiles>

Methyl $\beta$-D-Glucopyranoside

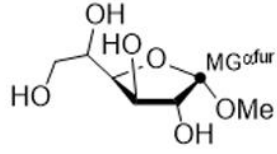

Methyl $\alpha$-D-Glucofuranoside $24 \%$ $3 \%$<smiles>CO[C@H]1O[C@@](O)(C(O)CO)[C@@H](O)[C@H]1O</smiles>

$\mathrm{OH}$

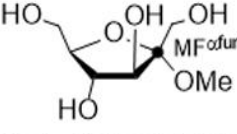

Methyl $\alpha$-D-Fructofuranoside

$9 \%$

OMe

Methyl $\beta$-D-Glucofuranoside Methyl $\alpha-D-F$ $36 \%$



$$
\mathrm{OH}
$$

Methyl $\beta$-D-Fructopyranoside $9 \%$

Figure $1 .{ }^{13} \mathrm{C}$ NMR spectrum and the ratio of carbohydrates obtained after $\mathrm{Al}(\mathrm{OTf})_{3}$-processing in methanol (step 1). Reaction conditions: glucose (50 mg), methanol $(2.00 \mathrm{~mL}), \mathrm{Al}(\mathrm{OTf})_{3}\left(20 \mathrm{~mol} \%\right.$ based on glucose), reflux at atmosphere pressure, $1 \mathrm{~h}$. Parameters of NMR analysis: $50 \mathrm{mg} \mathrm{sample,} \mathrm{D}_{2} \mathrm{O}(0.60 \mathrm{~mL}), 25{ }^{\circ} \mathrm{C} . \mathrm{G}^{\alpha}, \mathrm{G}^{\beta}$, $M^{\alpha}{ }^{\alpha p y r}, M^{\beta p y r}, M^{\alpha f u r}, M^{\beta f u r}, M^{\alpha f u r}, M^{\beta f u r}$, and $M^{\beta p y r}$ mean $\alpha$-D-glucopyranose, $\beta$-D-glucopyranose, methyl $\alpha$-D-glucopyranoside, methyl $\beta$-D-glucopyranoside, methyl $\alpha$-D-glucofuranoside, methyl $\beta$-D-glucofuranoside, methyl $\alpha$-D-fructofuranoside, methyl $\beta$-D-fructofuranoside, and methyl $\beta$-D-fructopyranoside, respectively. The anomeric $\mathrm{C}$ atoms $(\mathrm{C}-1)$ of the various compounds are labelled on the spectrum.

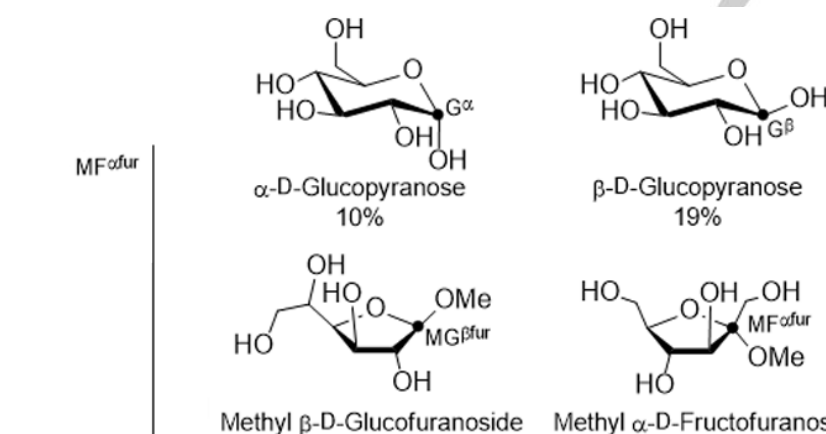

Methyl $\beta$-D-Glucofuranoside Methyl $\alpha$-D-Fructofuranoside $9 \%$





Methyl $\beta$-D-Glucopyranoside $1 \%$

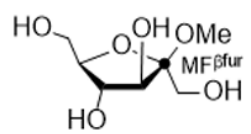

Methyl $\beta-D-F r u c t o f u r a n o s i d e$ $19 \%$

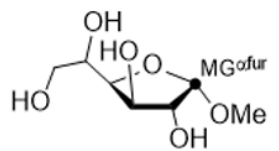

Methyl $\alpha$-D-Glucofuranoside

$8 \%$

OMe

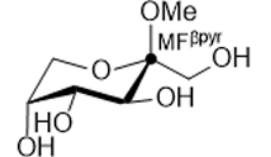

Methyl $\beta$-D-Fructopyranoside $11 \%$

Figure $2 .{ }^{13} \mathrm{C}$ NMR spectrum and the ratio of carbohydrates obtained after $\mathrm{Al}(\mathrm{OTf})_{3} / \mathrm{TBP}$-processing in methanol (step 1). Reaction conditions: glucose (50 mg), methanol $(2.00 \mathrm{~mL}), \mathrm{Al}(\mathrm{OTf})_{3}(20 \mathrm{~mol} \%$ based on glucose), TBP (60 mol\% based on glucose), reflux at atmosphere pressure, $36 \mathrm{~h}$. Parameters of NMR analysis:

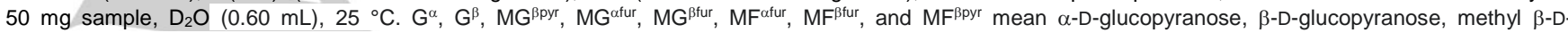
glucopyranoside, methyl $\alpha$-D-glucofuranoside, methyl $\beta$-D-glucofuranoside, methyl $\alpha$-D-fructofuranoside, methyl $\beta$-D-fructofuranoside, and methyl $\beta$-Dfructopyranoside, respectively. The anomeric $C$ atoms $(C-1)$ of the various compounds are labelled on the spectrum. 


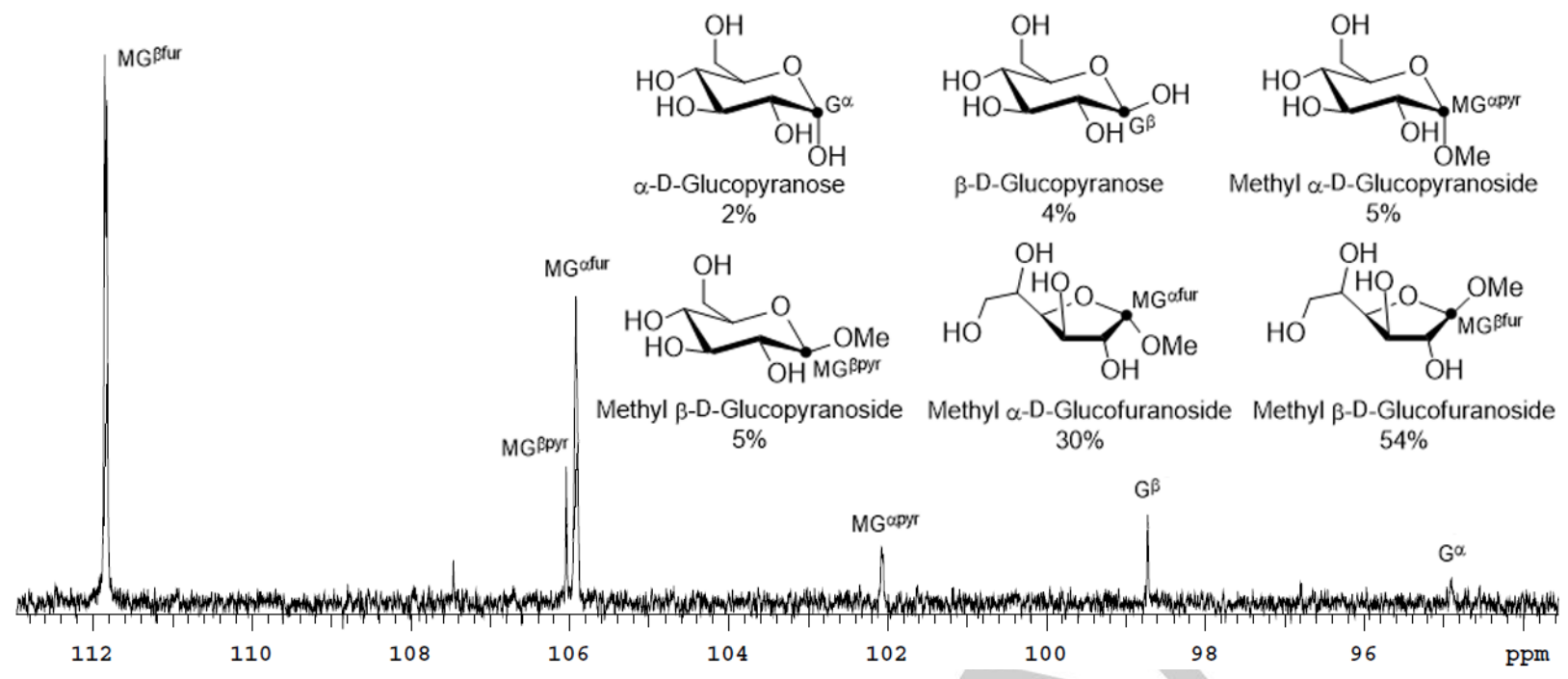

Figure $3 .{ }^{13} \mathrm{C}$ NMR spectrum and the ratio of carbohydrates obtained after TsOH-processing in methanol (step 1). Reaction conditions: glucose (50 mg), methano $(2.00 \mathrm{~mL}), \mathrm{TsOH}\left(20 \mathrm{~mol} \%\right.$ based on glucose), reflux at atmosphere pressure, $1 \mathrm{~h}$. Parameters of $\mathrm{NMR}$ analysis: $50 \mathrm{mg}$ sample, $\mathrm{D}_{2} \mathrm{O}(0.60 \mathrm{~mL}), 25{ }^{\circ} \mathrm{C} . \mathrm{G}^{\alpha}, \mathrm{G}^{\beta}$, $\mathrm{MG}^{\alpha \mathrm{pyr}}$, MG ${ }^{\beta p y r}, \mathrm{MG}^{\text {afur }}$, and MG $\mathrm{G}^{\beta f u r}$ mean $\alpha$-D-glucopyranose, $\beta$-D-glucopyranose, methyl $\alpha$-D-glucopyranoside, methyl $\beta$-D-glucopyranoside, methyl $\alpha$-Dglucofuranoside, and methyl $\beta$-D-glucofuranoside, respectively. The anomeric $\mathrm{C}$ atoms $(\mathrm{C}-1)$ of the various compounds are labelled on the spectrum.

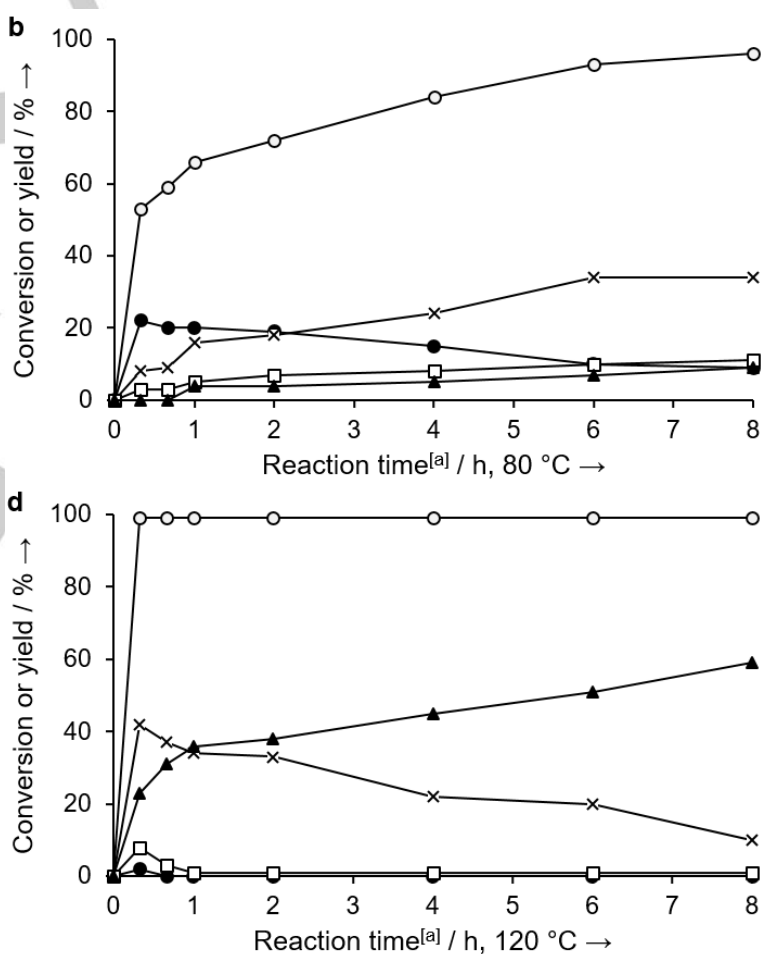

Figure 4. $\mathrm{Al}(\mathrm{OTf})_{3}$-catalyzed conversion of glucose via two-step process in methanol and water: a) Processing in methanol under solvent reflux at atmosphere pressure. b), c), d) Temperature of the processing in methanol $80,100,120^{\circ} \mathrm{C}$, respectively. [a] Time of the processing in methanol. Reaction conditions: glucose $(50 \mathrm{mg})$, methanol $(2 \mathrm{~mL}), \mathrm{Al}(\mathrm{OTf})_{3}(20 \mathrm{~mol} \%$ based on glucose), then solvent exchange with water $(2 \mathrm{~mL})$, solvent under reflux at atmosphere pressure $(1 \mathrm{~h})$ o conversion of glucose, $\bullet$ yield of fructose, $\times$ yield of MG, $\square$ total yield of HMF and MMF, $\Delta$ yield of MLev (identified immediately after the processing in methanol). 


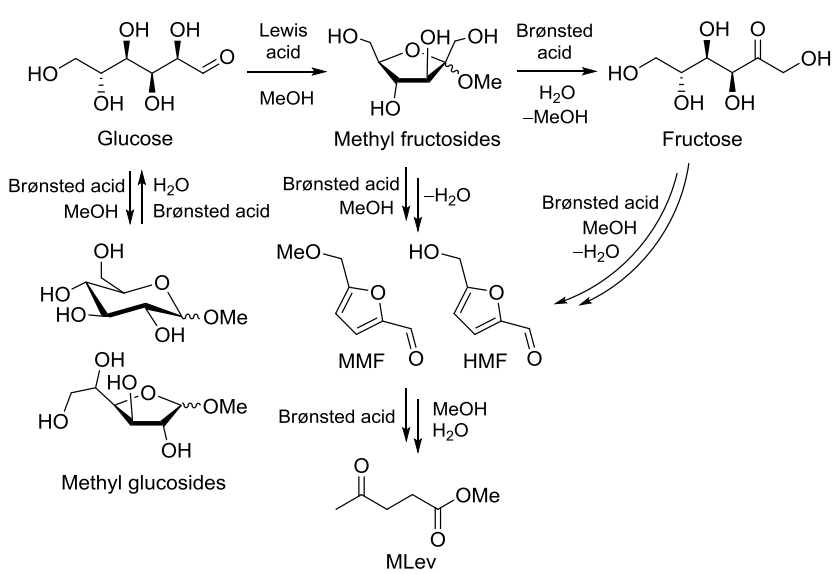

Scheme 2. Acid-catalyzed transformation of glucose into platform molecules in methanol and water, highlighting either Lewis acid- or Brønsted acid-catalysis at each step.

MLev is the major product at elevated temperature, in an excellent $59 \%$ yield in a highly selective reaction $\left(120^{\circ} \mathrm{C}, 8 \mathrm{~h}\right.$, Figure $4 \mathrm{~d}$; the yield remains unchanged at $12 \mathrm{~h}$ and $18 \mathrm{~h}$ ). Model transformations of fructose and $\mathrm{HMF}$ using $\mathrm{TsOH}$ as catalyst (Table S5) highlight the notion that the dehydration/rehydration processes are catalyzed by Brønsted acids. Scheme 2 provides a summary of the conversion of glucose in methanol and water, as discussed above, distinguishing between Lewis acid-promoted reactions and Brønsted acid-catalyzed transformations.

Various other metal triflates and Brønsted acids transform glucose into derivative products MG and/or MLev in the two-step transformation of glucose in methanol and water, to a greater or lesser extent. Table 2 perfectly exemplifies the interplay between Brønsted and Lewis acidity in these conversions of glucose to product. Typical Brønsted acid catalysts or Lewis acid-assisted Brønsted acids promoted the transformation of glucose into MG, especially highlighted by $\mathrm{TsOH}$ (MG yield $93 \%$, $\alpha$-anomer as major product). In these reactions, the thermodynamic preference for methyl glucopyranosides was evident with minimum formation of the kinetic product methyl glucofuranosides (determined by quantitative NMR analysis of the product mixture after Step 1, Figures S7 and S8). ${ }^{[8]}$ The anomalous apparent diminished Brønsted acid activity of $\mathrm{La}(\mathrm{OTf})_{3} / \mathrm{H}_{3} \mathrm{PO}_{4}$, evidenced by only $77 \%$ yield of MG compared to superior yields afforded by weaker Brønsted acids, likely relates to precipitation of the catalyst at elevated temperature, with a concomitant reduction of the reaction rate, as is typical for heterogeneous systems. ${ }^{[29]}$ Surprisingly, Lewis acidic catalysts AgOTf, $\mathrm{La}(\mathrm{OTf})_{3}$ and $\mathrm{Y}(\mathrm{OTf})_{3}$, with low Brønsted acidity at low temperature (Table 1), showed high selectivity towards $M G$ at elevated temperature, which relies upon Brønsted acid activity. $\mathrm{pH}$ measurements of solutions of these catalysts at $20^{\circ} \mathrm{C}$ and $40^{\circ} \mathrm{C}$ show the increased Brønsted acidity in methanol and water (Table 1) associated with elevated temperatures. This would be even higher at the elevated temperatures under which the reactions are performed. This suggests that the complexation of the catalyst and solvent leads to sufficient Brønsted acidity under more forcing reaction conditions, but with insufficient Lewis or Brønsted acidity to promote subsequent reactions, giving high selectivity. Catalysts considered to be hard Lewis acids (e.g., $\mathrm{Hf}(\mathrm{OTf})_{4}, \mathrm{Sn}(\mathrm{OTf})_{2}$ and $\ln (\mathrm{OTf})_{3}$, which also produce high Brønsted acidity) delivered excellent outcomes towards MLev (Tables 1, 2). MLev is formed by Lewis acid-catalyzed isomerization of glucose into fructose followed by (Lewis acid-assisted) Brønsted acid-catalyzed dehydration/rehydration processes. $\mathrm{Sn}(\mathrm{OTf})_{2}$ offers superb selectivity towards desirable products without significant formation of by-product humins that were observed in aqueous media at lower temperatures, affording MLev in 67\% yield.

\begin{tabular}{|c|c|c|c|c|c|}
\hline Catalyst & $\begin{array}{l}\text { Conv } \\
{[\%]}\end{array}$ & $\begin{array}{l}\text { Fructose } \\
\text { yield [\%] }\end{array}$ & $\begin{array}{l}\text { MG } \\
\text { yield [\%] }\end{array}$ & $\begin{array}{l}\mathrm{HMF} \text { and MMF } \\
\text { yield [\%] }\end{array}$ & $\begin{array}{l}\text { MLev } \\
\text { yield }^{[b]}[\%]\end{array}$ \\
\hline $\mathrm{Al}(\mathrm{OTf})_{3}$ & 99 & 0 & 10 & 0 & 59 \\
\hline $\begin{array}{l}\mathrm{La}(\mathrm{OTf})_{3} / \\
\mathrm{H}_{3} \mathrm{PO}_{4}\end{array}$ & 84 & 0 & 71 & 0 & 7 \\
\hline $\mathrm{Hf}(\mathrm{OTf})_{4}$ & 90 & 0 & 14 & 0 & 39 \\
\hline $\mathrm{TsOH}$ & 93 & 0 & 93 & 0 & 0 \\
\hline $\mathrm{H}_{3} \mathrm{PO}_{4}$ & 13 & 0 & 13 & 0 & 0 \\
\hline $\begin{array}{l}\mathrm{La}(\mathrm{OTf})_{3} / \\
\mathrm{TsOH}\end{array}$ & 89 & 0 & 89 & 0 & 0 \\
\hline $\mathrm{Sn}(\mathrm{OTf})_{2}$ & $\begin{array}{l}90 \\
97^{[c]}\end{array}$ & $\begin{array}{l}0 \\
0^{[c]}\end{array}$ & $\begin{array}{l}46 \\
18^{[c]}\end{array}$ & $\begin{array}{l}1 \\
0^{[c]}\end{array}$ & $\begin{array}{l}43 \\
67^{[c]}\end{array}$ \\
\hline $\ln (\mathrm{OTf})_{3}$ & 99 & 0 & 8 & 1 & 52 \\
\hline $\mathrm{AgOTf}$ & 95 & 0 & 90 & 0 & 0 \\
\hline LiOTf & 13 & 8 & 0 & 0 & 0 \\
\hline $\mathrm{La}(\mathrm{OTf})_{3}$ & 99 & 0 & 89 & 1 & 9 \\
\hline $\mathrm{Y}(\mathrm{OTf})_{3}$ & 99 & 0 & 72 & 0 & 9 \\
\hline
\end{tabular}

[a] Yields are specified in mol\% based on glucose; '0' or '99' for the product were identified on the basis of trace analysis by HPLC. Reaction conditions: glucose $(50 \mathrm{mg})$, methanol $(2 \mathrm{~mL})$, catalyst (20 mol\% based on glucose), $120^{\circ} \mathrm{C}, 8 \mathrm{~h}$, then solvent exchange with water $(2 \mathrm{~mL})$, reflux at atmosphere pressure, $1 \mathrm{~h}$. [b] Yield of MLev was identified immediately after the processing in methanol. [c] Reaction temperature $=140^{\circ} \mathrm{C}$, time $=4 \mathrm{~h}$.

\section{Conclusions}

This systematic study of a range of metal triflates and some associated (induced) Brønsted acid systems shows that the selectivity is determined by the dominating Brønsted or Lewis acidity. The nature of the dominant acidity can be manipulated by varying the reaction conditions. Firstly, this includes the addition of a protic acid to form Brønsted acidic combined acid complexes, such as $\mathrm{La}(\mathrm{OTf})_{3} / \mathrm{H}_{3} \mathrm{PO}_{4}$, which promote high conversion of 
glucose into disaccharides in aqueous solvent. Secondly, it includes the addition of the Brønsted base TBP to inhibit Brønsted acidity and thereby enhance the yield of fructose in two-step processing in methanol and water. The activities of metal triflates can be dramatically altered by raising the reaction temperature: whereas some less active metal triflates show poor catalyst activity at lower temperatures, their activity is enhanced at elevated temperatures and is accompanied by very high selectivity to product, being MG or MLev, with very little byproduct formation. It is noteworthy that Lewis acids which offer the lowest Brønsted acidity at mild conditions, namely AgOTf, $\mathrm{La}(\mathrm{OTf})_{3}$ and $\mathrm{Y}(\mathrm{OTf})_{3}$, promoted Brønsted acid-catalyzed conversion of glucose into $M G$ at higher temperature, and thus become a source of hydrogen cation under such conditions, but in highly selective processes. Alternatively, harder Lewis acids (i.e. acids that preferentially interact with protic solvents) with enhanced Brønsted acidity in water and methanol (e.g., Hf(OTf $)_{4}$, $\mathrm{Sn}(\mathrm{OTf})_{2}, \operatorname{In}(\mathrm{OTf})_{3}$ and $\left.\mathrm{Al}(\mathrm{OTf})_{3}\right)$ can efficiently catalyze the transformation of glucose into MLev via an initial Lewis acidcatalyzed isomerization step. These transformations of glucose employing metal triflates affords a deeper insight of the overall role of the acid catalyst in the production of target platform molecules under specified reaction conditions. These insights provide a springboard for future studies towards the selective acid-catalyzed conversion of glucose, as well as other naturally abundant carbohydrates, into a range of functional molecules. Among the options of catalyst for the processing of native biomass such as lignocellulose, metal triflates hold significant promise towards sustainable industrial development.

\section{Experimental Section}

Reagents and metal triflate catalysts $\left(\mathrm{Hf}(\mathrm{OTf})_{4}, \mathrm{Sn}(\mathrm{OTf})_{2}, \ln (\mathrm{OTf})_{3}\right.$, $\mathrm{Al}(\mathrm{OTf})_{3}, \mathrm{AgOTf}, \mathrm{LiOTf}, \mathrm{La}(\mathrm{OTf})_{3}$ or $\left.\mathrm{Y}(\mathrm{OTf})_{3}\right)$ and phosphoric acid $\left(\mathrm{H}_{3} \mathrm{PO}_{4}\right.$, $85 \mathrm{wt} \%$ aqueous solution) were used as supplied from commercial sources $p$-Toluenesulfonic acid monohydrate was dried under reduced pressure $\left(60{ }^{\circ} \mathrm{C}, 1 \mathrm{mbar}, 12 \mathrm{~h}\right)$ to generate anhydrous TsOH. HPLC grade solvents were employed for experiments. Methanol was dried over activated $3 \AA$ molecular sieves, accordingly to the established optimum method. ${ }^{[30]}$ The analytical data for synthesized products described in this manuscript have

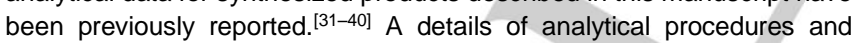
theoretical methods are specified in SI.

\section{Acid-catalyzed conversion of glucose in water}

Glucose $(50 \mathrm{mg})$, water $(2.00 \mathrm{~mL})$ and acid catalyst $(20 \mathrm{~mol} \%$ based on glucose) were introduced to a round-bottom flask equipped with a condenser and magnetic follower. The mixture was heated and stirred under reflux at atmosphere pressure for $2 \mathrm{~h}$. The reaction was quenched by the addition of an aqueous solution of sodium hydrogen carbonate (2.0 $\mathrm{mL}, 0.05 \mathrm{M}$ ) to neutralize the catalyst. The neutralized aqueous systems were centrifuged $(20,000 \times \mathrm{g}$ for $10 \mathrm{~min})$, and decanted, and recovered solutions were analyzed using an HPLC system, as detailed in SI, to provide the results detailed in the main text.

For the targeted synthesis of disaccharides, glucose $(500 \mathrm{mg})$, water (1.65 $\mathrm{mL}$ ) and catalyst ( $20 \mathrm{~mol} \%$ based on glucose) were charged to a roundbottom flask equipped with a condenser, and magnetic follower and the reaction mixture was heated and agitated under reflux at atmosphere pressure for $12 \mathrm{~h}$. The reaction mixture was diluted with aqueous sodium hydrogen carbonate $(40.0 \mathrm{~mL}, 0.05 \mathrm{M})$. An aliquot of the neutralized aqueous system was centrifuged $(20,000 \times \mathrm{g}$ for $10 \mathrm{~min})$ and decanted, and the recovered solutions were analyzed using the HPLC system to provide the results detailed in the main text. A detailed method for preparative separation of carbohydrates is presented in SI. NMR, IR, and MS spectra for the isolated disaccharides were assigned by comparison with literature data and spectra produced from an authentic commercial sample of isomaltose. ${ }^{[31-34]}$

Isomaltose (reference sample). ${ }^{[31-34]}{ }^{13} \mathrm{C}$ NMR $\left(125 \mathrm{MHz}, \mathrm{D}_{2} \mathrm{O}, 25^{\circ} \mathrm{C}\right.$, $\left.\left[\mathrm{D}_{4}\right] \mathrm{TMSP}\right): \delta=97.9,96.0,92.1,75.9,74.2,74.0,73.0,71.7,71.4,71.3$, 70.0, 69.5, 69.4, 69.3, 65.7, 65.6, 60.4; IR (neat): $v_{\max }=3267,2922,1643$, 1421, 1348, 1263, 1149, 1102, 1007, 913, 842, 764, $501 \mathrm{~cm}^{-1}$; HRMS (ESI): $\mathrm{m} / \mathrm{z}$ : calcd for $\mathrm{C}_{12} \mathrm{H}_{21} \mathrm{O}_{11}[\mathrm{M}-\mathrm{H}]^{-}: 341.1089$, found: 341.1096 .

Isolated disaccharides. ${ }^{[31-34]}{ }^{13} \mathrm{C}$ NMR $\left(125 \mathrm{MHz}, \mathrm{D}_{2} \mathrm{O}, 25^{\circ} \mathrm{C},\left[\mathrm{D}_{4}\right] \mathrm{TMSP}\right)$ : $\delta=97.9,96.0,92.1,75.9,74.2,74.0,73.0,72.4,71.7,71.4,71.3,70.0$, $69.6,69.5,69.4,69.3,65.7,65.6,60.4$; IR (neat): $v_{\max }=3261,2921,1642$, 1567, 1421, 1353, 1149, 1099, 1011, 918, 842, 766, $495 \mathrm{~cm}^{-1}$; HRMS (ESI): $m / z$ : calcd for $\mathrm{C}_{12} \mathrm{H}_{21} \mathrm{O}_{11}[\mathrm{M}-\mathrm{H}]^{-}: 341.1089$, found: 341.1088 .

\section{Two-step acid-catalyzed conversion in methanol and water}

Glucose $(50 \mathrm{mg})$, methanol $(2.00 \mathrm{~mL})$ and acid catalyst $(20 \mathrm{~mol} \%$ based on glucose), and in some instances base (2,6-di-tert-butyl-4methylpyridine, $60 \mathrm{~mol} \%$ based on glucose), were introduced to a roundbottom flask equipped with a condenser and magnetic follower. The mixture was heated and stirred under reflux at atmosphere pressure for a fixed period of time (step 1). Then methanol was evaporated under reduced pressure $\left(30^{\circ} \mathrm{C}, 90 \mathrm{mbar}\right)$ and water $(2.00 \mathrm{~mL})$ was added to the reactor (solvent exchange). The resulting mixture was heated and stirred under reflux at atmosphere pressure for $1 \mathrm{~h}$ (step 2). The reaction was quenched by the addition of an aqueous solution of sodium hydrogen carbonate $(2.00 \mathrm{~mL}, 0.05 \mathrm{M})$ and the mixture was centrifuged $(20,000 \times \mathrm{g}$ for $10 \mathrm{~min}$ ) and decanted. The recovered solutions were analyzed using an HPLC system, as detailed in $\mathrm{SI}$, to provide the results detailed in the main text.

Reactions at elevated temperatures of $80-120{ }^{\circ} \mathrm{C}$ in step 1 were conducted in a sealed glass pressure tube. Glucose $(50 \mathrm{mg})$, methanol $(2.00 \mathrm{~mL})$ and acid catalyst ( $20 \mathrm{~mol} \%$ based on glucose) were introduced to a glass pressure tube equipped with a magnetic follower and the reactor was sealed. The mixture was heated and stirred at the predetermined temperature for a fixed period of time (step 1). After cooling, the mixture was transferred to a round-bottom flask and methanol was evaporated under reduced pressure $\left(30^{\circ} \mathrm{C}, 90\right.$ mbar). Then water $(2.00 \mathrm{~mL})$ was added to the reactor (solvent exchange) and the resulting mixture was heated and stirred under reflux at atmosphere pressure for $1 \mathrm{~h}$ (step 2). The reaction was quenched by the addition of an aqueous solution of sodium hydrogen carbonate $(2.00 \mathrm{~mL}, 0.05 \mathrm{M})$ and the mixture was centrifuged $(20,000 \times \mathrm{g}$ for $10 \mathrm{~min})$ and decanted. The recovered solutions were analyzed using an HPLC system to provide the results detailed in the main text. Additional details of synthesis methods and preparative isolation of products are presented in SI.

Methyl $\alpha$-D-glucopyranoside. ${ }^{[35-37]}{ }^{1} \mathrm{H}$ NMR $\left(500 \mathrm{MHz}, \mathrm{D}_{2} \mathrm{O}, 25{ }^{\circ} \mathrm{C}\right.$ [D4]TMSP): $\delta=4.82(\mathrm{~d}, J=3.5 \mathrm{~Hz}, 1 \mathrm{H}), 3.88(\mathrm{dd}, J=12.5,2.0 \mathrm{~Hz}, 1 \mathrm{H})$, 3.76 (dd, $J=12.5,5.5 \mathrm{~Hz}, 1 \mathrm{H}), 3.69-3.63(\mathrm{~m}, 2 \mathrm{H}), 3.56$ (dd, $J=9.5,3.8$ $\mathrm{Hz}, 1 \mathrm{H}), 3.43(\mathrm{~s}, 3 \mathrm{H}), 3.41-3.38(\mathrm{~m}, 1 \mathrm{H}) ;{ }^{13} \mathrm{C}$ NMR $\left(125 \mathrm{MHz}, \mathrm{D}_{2} \mathrm{O}, 25^{\circ} \mathrm{C}\right.$, [D 4 TMSP): $\delta=102.2,102.1,76.0,74.4,74.1,72.4,63.4,57.9$; IR (neat): $v_{\max }=3542,3232,2912,1460,1430,1372,1340,1302,1226,1185,1103$, 1025, 991, 898, 842, 745, $666 \mathrm{~cm}^{-1}$; HRMS (ESI): $\mathrm{m} / \mathrm{z}$. calcd for $\mathrm{C}_{7} \mathrm{H}_{13} \mathrm{O}_{6}$ $[\mathrm{M}-\mathrm{H}]^{-}:$193.0718, found: 193.0715 . 
HMF. ${ }^{[38]} \mathrm{TLC}: \mathrm{R}_{f}=0.213\left(1.5: 1\right.$ hexane/EtOAc; UV, $\left.\mathrm{KMnO}_{4}\right) ;{ }^{1} \mathrm{H}$ NMR (500 $\left.\mathrm{MHz}, \mathrm{CDCl}_{3}, 25^{\circ} \mathrm{C}\right): \delta=9.56(\mathrm{~d}, J=1.0 \mathrm{~Hz}, 1 \mathrm{H}), 7.21(\mathrm{~d}, J=3.5 \mathrm{~Hz}, 1 \mathrm{H})$, $6.50(\mathrm{~d}, J=3.5 \mathrm{~Hz}, 1 \mathrm{H}), 4.70(\mathrm{~s}, 2 \mathrm{H}), 2.97$ (br s, $1 \mathrm{H}, \mathrm{OH}) ;{ }^{13} \mathrm{C}$ NMR $(125$ $\left.\mathrm{MHz}, \mathrm{CDCl}_{3}, 25^{\circ} \mathrm{C}\right): \delta=177.7,160.7,152.3,123.0,110.0,57.5$; IR (neat): $V_{\max }=3339,3120,2841,1657,1582,1519,1396,1368,1336,1278,1188$, 1070, 1017, 986, 965, 806, 768, $511 \mathrm{~cm}^{-1}$; HRMS (ESI): $\mathrm{m} / z$ : calcd for $\mathrm{C}_{6} \mathrm{H}_{6} \mathrm{O}_{3} \mathrm{H}[\mathrm{M}+\mathrm{H}]^{+}:$127.0390, found: 127.0379 .

MMF. ${ }^{[39]}$ TLC: $\mathrm{R}_{f}=0.563$ (1.5:1 hexane/EtOAc; UV, $\left.\mathrm{KMnO}_{4}\right) ;{ }^{1} \mathrm{H}$ NMR (500 $\left.\mathrm{MHz}, \mathrm{CDCl}_{3}, 25^{\circ} \mathrm{C}\right): \delta=9.61(\mathrm{~s}, 1 \mathrm{H}), 7.21(\mathrm{~d}, J=3.5 \mathrm{~Hz}, 1 \mathrm{H}), 6.52(\mathrm{~d}, J=$ $3.5 \mathrm{~Hz}, 1 \mathrm{H}), 4.48(\mathrm{~s}, 2 \mathrm{H}), 3.42(\mathrm{~s}, 3 \mathrm{H}) ;{ }^{13} \mathrm{C} \mathrm{NMR}\left(125 \mathrm{MHz}, \mathrm{CDCl}_{3}, 25^{\circ} \mathrm{C}\right)$ : $\delta=177.7,158.2,152.6,121.8,111.1,66.5,58.7 ;$ IR (neat): $v_{\max }=3119$, 2930, 2824, 1673, 1584, 1520, 1450, 1401, 1370, 1275, 1192, 1092, 1022 , 1001, 970, 944, 907, 810, 784, 756, 732, $509 \mathrm{~cm}^{-1}$; HRMS (ESI): $\mathrm{m} / \mathrm{z}$ calcd for $\mathrm{C}_{7} \mathrm{H}_{8} \mathrm{O}_{3} \mathrm{H}[\mathrm{M}+\mathrm{H}]^{+}:$141.0546, found: 141.0536 .

MLev. ${ }^{[40]} \mathrm{TLC}: \mathrm{R}_{f}=0.438\left(1.5: 1\right.$ hexane/EtOAc; $\left.\mathrm{KMnO}_{4}\right) ;{ }^{1} \mathrm{H}$ NMR $(500$ $\left.\mathrm{MHz}, \mathrm{CDCl}_{3}, 25^{\circ} \mathrm{C}\right): \delta=3.67(\mathrm{~s}, 3 \mathrm{H}), 2.75(\mathrm{t}, J=7.0 \mathrm{~Hz}, 2 \mathrm{H}), 2.57$ (t, $J=$ $7.0 \mathrm{~Hz}, 2 \mathrm{H}), 2.19(\mathrm{~s}, 3 \mathrm{H}) ;{ }^{13} \mathrm{C} \mathrm{NMR}\left(125 \mathrm{MHz}, \mathrm{CDCl}_{3}, 25^{\circ} \mathrm{C}\right): \delta=206.6$, $173.2,51.8,37.9,29.8,27,7$; IR (neat): $v_{\max }=3000,2954,1736,1718$, $1438,1362,1315,1213,1162,1068,1029,1000,970,894,812,766,574$ $480 \mathrm{~cm}^{-1}$; HRMS (ESI): $\mathrm{m} / z$ : calcd for $\mathrm{C}_{6} \mathrm{H}_{9} \mathrm{O}_{3}[\mathrm{M}-\mathrm{H}]^{-}: 129.0557$, found: 129.0549 .

\section{Acknowledgements}

We thank the University of Technology Sydney for financial support.

Keywords: catalysis $\cdot$ acidity $\cdot$ carbohydrates $\bullet$ green chemistry

[1] I. Bodachivskyi, U. Kuzhiumparambil, D.B.G. Williams, ChemSusChem 2018, 11, 642-660.

[2] A. Corma, S. Iborra, A. Velty, Chem. Rev. 2007, 107, 2411-2502.

[3] H. Li, S. Yang, S. Saravanamurugan, A. Riisager, ACS Catal. 2017, 7, 3010-3029.

[4] I. Delidovich, R. Palkovits, ChemSusChem 2016, 9, 547-561.

[5] M. Dusselier, B.F. Sels, in Selective catalysis for renewable feedstocks and chemicals. Top. Cur. Chem., Vol 353 (Ed.: K. Nicholas), Springer, Cham, 2014, pp. 85-125.

[6] X. Hu, C. Lievens, A. Larcher, C.Z. Li, Bioresour. Technol. 2011, 102, 10104-10113.

[7] S. Kobayashi, S. Nagayama, T. Busujima, J. Am. Chem. Soc. 1998, 120 , 8287-8288.

[8] S. Saravanamurugan, A. Riisager, E. Taarning, S. Meier, ChemCatChem 2016, 8, 1-6.

[9] M. Moliner, Y. Román-Leshkov, M.E. Davis, Proc. Natl. Acad. Sci. U.S.A. 2010, 107, 6164-6168.

[10] R. Bermejo-Deval, R.S. Assary, E. Nikolla, M. Moliner, Y. RománLeshkov, S.-J. Hwang, A. Palsdottir, D. Silverman, R.F. Lobo, L.A Curtiss, M.E. Davis, Proc. Natl. Acad. Sci. U.S.A. 2012, 109, 9727-9732.
[11] S. Kobayashi, M. Sugiura, H. Kitagawa, W.W.-L. Lam, Chem. Rev. 2002 102, 2227-2302

[12] D.B.G. Williams, M.L. Shaw, T. Hughes, Organometallics 2011, 30 4968-4973.

[13] D.B.G. Williams, M.S. Sibiya, P.S. van Heerden, Fuel Process. Technol. 2012, 94, 75-79

[14] F.-F. Wang, C.-L. Liu, W.-S. Dong, Green Chem. 2013, 15, 2091-2095.

[15] K. Tominaga, A. Mori, Y. Fukushima, S. Shimada, K. Sato, Green Chem. 2011, 13, 810-812

[16] M. Dusselier, R. De Clercq, R. Cornelis, B.F. Sels, Catalysis Today 2017 279, 339-344

[17] S. Saravanamurugan, M. Paniagua, J.A. Melero, A. Riisager, J. Amer. Chem. Soc. 2013, 135, 5246-5249.

[18] G. Tsilomelekis, M.J. Orella, Z. Lin, Z. Cheng, W. Zheng, V. Nikolakis D.G. Vlachos, Green Chem. 2016, 18, 1983-1993.

[19] E. Fischer, Ber. Dtsch. Chem. Ges. 1890, 23, 3687-3691.

[20] C. Vanderghem, P. Boquel, C. Blecker, M. Paquot, Appl. Biochem. Biotechnol. 2010, 160, 2300-2307.

[21] M. Díez-Municio, A. Montilla, F.J. Moreno, M. Herrero, Green Chem. 2014, 16, 2219-2226.

[22] S. Pedersen, H. Hendriksen (Novozymes A/S), US 20030059901 A1 2003

[23] H. Yamamoto, K. Futatsugi, Angew. Chem. Int. Ed. 2005, 44, 1924-1942; Angew. Chem. 2005, 117, 1958-1977.

[24] D.B.G. Williams, M. Lawton, J. Mol. Catal. A: Chem. 2010, 317, 68-71.

[25] S. Saravanamurugan, A. Riisager, Catal. Sci. Technol. 2014, 4, 3186 3190.

[26] M. Paniagua, S. Saravanamurugan, M. Melian-Rodriguez, J.A. Melero, A. Riisager, ChemSusChem 2015, 8, 1088-1094.

[27] H.C. Brown, B. Kanner, J. Amer. Chem. Soc. 1966, 88, 986-992.

[28] E.S. Stoyanov, I.V. Stoyanova, C.A. Reed, Chem. Sci. 2011, 2, 462-472.

[29] B. Cornils, W.A. Herrmann, C.-H. Wong, H.-W. Zanthoff, Catalysis from A to Z: A Concise Encyclopedia, 4 Volume Set, 4th ed., Wiley- $\mathrm{VCH}$ Weinheim, 2013.

[30] D.B.G. Williams, M. Lawton, J. Org. Chem. 2010, 75, 8351-8354

[31] C. Arnosti, D.J. Repeta, Starch/Stärke 1995, 47, 73-75.

[32] M. Mizuno, K. Goto, T. Miura, T. Inazu, QSAR Comb. Sci. 2006, 25, 742 752.

[33] T.T. Fang, J. Zirrolli, B. Bendiak, Carbohydr. Res. 2007, 342, 217-235.

[34] S.S. van Leeuwen, B.R. Leeflang, G.J. Gerwig, J.P. Kamerling, Carbohydr. Res. 2008, 343, 1114-1119.

[35] A.D. Bain, D.R. Eaton, R.A. Hux, J.P.K. Tong, Carbohydr. Res. 1980, 84 1-12.

[36] M.R.C. Couri, E.A. Evangelista, R.B. Alves, M.A.F. Prado, R.P.F. Gil, M.V. De Almeida, D.S. Raslan, Synth. Commun. 2005, 35, 2025-2031.

[37] X. Zhu, T. Sato, Rapid Commun. Mass Spectrom. 2007, 21, 191-198.

[38] N. Murai, M. Yonaga, K. Tanaka, Org. Lett. 2012, 14, 1278-1281.

[39] H. Quiroz-Florentino, R. Aguilar, B.M. Santoyo, F. Díaz, J. Tamariz, Synthesis 2008, 7, 1023-1028.

[40] J. Izquierdo, S. Rodríguez, F.V. González, Org. Lett. 2011, 13, 3856 3859 


\section{Entry for the Table of Contents}

\section{FULL PAPER}

The work discloses a systematic study with fundamental insights relating to Brønsted and Lewis acidity in metal triflate-catalyzed transformations of glucose in water and methanol. It reveals the dominant type of acidity and reaction conditions to obtain isomaltose, fructose, methyl glucosides, or methyl levulinate in highly selective processes, and how to optimize this acidity by manipulating reaction conditions.



Iurii Bodachivskyi, Unnikrishnan Kuzhiumparambil, D. Bradley G. Williams *

Page No. - Page No.

A systematic study of metal triflates in catalytic transformations of glucose in water and methanol: identifying the interplay of Brønsted and Lewis acidity 